\title{
Fat absorption in pancreatic deficiency in rats
}

\author{
J. MASAREI ${ }^{1}$ AND W. J. SIMMONDS \\ From the Department of Physiology, the University of Western Australia, \\ Nedlands, Western Australia
}

EDITORIAL SYNOPSIS Bile or pancreatic juices are essential for the absorption of triglyceride from the small intestine but not for the absorption of fatty acid. In pancreatic fistula animals some lipolytic activity remains in the small intestine which might account for the absorption of some triglyceride. This absorption is improved by returning bicarbonate with bile salts to the small intestine.

Although it is clear that the principal effect of pancreatic deficiency is malabsorption of triglyceride, there are several points on which there is disagreement. Some triglyceride can be absorbed in the absence of pancreatic juice provided that bile is present, but opinions differ on whether any is absorbed when both bile and pancreatic juice are absent. Cohen (1961) found that dogs in which both bile and pancreatic juice were excluded from the small intestine absorbed about the same proportion of ingested triglyceride, i.e., about $40 \%$, as dogs with biliary deficiency alone. Kim and Bollman(1954) showed that rats absorbed virtually no triglyceride when both secretions were absent.

There has also been disagreement on the efficiency of fatty acid absorption in pancreatic deficiency. Some have found normal absorption provided that bile was present (Cohen, 1961; Karvinen, Lin, and Ivy, 1957). Others have concluded that absorption was depressed to some extent (Pessoa, Kim, and Ivy, 1953; Vermeulen, Owens, and Dragstedt, 1943). An improvement following administration of bicarbonate has been claimed (Cohen and Annegers, 1953) and denied (Karvinen et al., 1957).

In previous work, unemulsified fat has been given and information on the completeness of pancreatic exclusion has often been omitted. In the present experiments olive oil and oleic acid were administered as fine emulsions which were stable in the intestinal lumen. Quantitative estimates of lipase in the intestinal contents were performed. Unanaesthetized, restrained rats were used with a combined biliary and pancreatic fistula. They were given steady intraduodenal infusion of fat or saline, and with the test meal received sodium taurocholate,

'Part of the work reported in this paper was performed during tenure of the James and Sith Annie Chesters Scholarship and under a grant from the National Health and Medical Research Council of Australia. taurocholate plus bicarbonate, or no replacement. Absorption was estimated from the amount of fat subsequently recovered from the lumen. Under these conditions it appeared that any absorption of triglyceride was dependent on residual lipolytic activity and that fatty acid absorption was unaffected by the combined absence of bile and pancreatic juice.

\section{GENERAL PROCEDURE}

Forty-eight hours after operation, commencing about 10 a.m., the test material was infused into the duodenum at a constant rate for four hours. Immediately thereafter the animals were reanaesthetized, and the stomach, small intestine, and caecum were removed separately between ligatures and irrigated with saline to recover the contents (Aberdeen, Shepherd, and Simmonds, 1960).

There were four groups of animals: (1) indwelling duodenal tube but no fistula; (2) combined biliarypancreatic fistula, but no replacements; (3) combined fistula and taurocholate, $30 \mathrm{mg} . / \mathrm{ml}$. given at the rate of $16.5 \mathrm{mg}$./hr. with the test meal; (4) combined fistula and taurocholate as for group 3 plus bicarbonate $7.5 \mathrm{mg} . / \mathrm{ml}$. at the rate of $4.1 \mathrm{mg} . / \mathrm{hr}$. with the test meal.

Each of the following test meals was given to five animals of each group: emulsified olive oil, emulsified oleic acid, and $0.85 \%$ (w/v) NaCl solution. The emulsions were prepared by the Upjohn Company and consisted of $12 \%(\mathrm{w} / \mathrm{v})$ olive oil or oleic acid in $5 \%$ dextrose with a polyoxyethylene-ethylene oxide (Pluronic F68), and lecithin as emulsifiers. The majority of the particles were below $0.3 \mu$ in size and control experiments showed that stability was maintained in the intestinal lumen.

The total volume of fluid infused was always $0.55 \mathrm{ml} / \mathrm{hr}$. with the exception of one subgroup, and the dose of fat or fatty acid was approximately $220 \mu \mathrm{Eq}$. of saponifiable fat per hour, representing about $65 \mathrm{mg}$. of olive oil or oleic acid per hour. In the subgroup mentioned, oleic acid was given in the same dose but in $1.64 \mathrm{ml} . / \mathrm{hr}$., without significantly affecting the results. 


\section{ANALYTICAL METHODS}

Saponifiable fat was estimated by the method of van de Kamer, ten Bokkel Huinink, and Weyers (1949).

Lipolytic activity was measured by two methods, using olive oil emulsified with acacia as the substrate. In the main series $1 \mathrm{ml}$. aliquots of intestinal washings were incubated at $37^{\circ} \mathrm{C}$. for six hours, in a reaction mixture buffered at $p \mathrm{H} 8.0$ (Tietz, Borden, and Stepleton, 1959). Tests were also performed on contents heated to $70^{\circ} \mathrm{C}$. for $10 \mathrm{~min}$., which is known to inactivate pancreatic lipase. To compare the properties of the residual lipolytic activity found in diverted animals with the pancreatic lipase in the control group, the initial rate of lipolysis was determined by continuous titration at constant $p \mathrm{H}$ (Desnuelle, Constantin, and Baldy, 1955), using a calibrated electrically driven syringe, manually controlled to add alkali. Readings were taken every $2 \mathrm{~min}$. for eight minutes. The reaction mixture was stirred by a stream of nitrogen bubbles. An excess of olive oil $(4 \%$ $\mathrm{w} / \mathrm{v})$ was used so that the rate of lipolysis was proportional to the activity of the enzyme. Except where the effects of $p \mathrm{H}$, etc., were being determined, the reaction mixture was kept at $p \mathbf{H} 8 \cdot 4$. One ml. aliquots of intestinal contents were used, except that in some experiments contents were pooled and freeze-dried to concentrate the activity.

Tryptic activity was assessed by the method of Andersen and Early (1942), which tests the ability of the contents to digest gelatin.

For thin-layer chromatography, animals were prepared as in groups 2, 3, and 4 above, and olive oil infused in the usual dose for four hours. The small intestinal contents were washed out as before, and the lipids extracted by the method of Borgström, Lundh, and Hofmann (1963). The extract was evaporated under reduced pressure, and taken up in chloroform. Thin-layer chromatography was performed on silica gel, using a hexane-ether-acetic acid solvent mixture $(80: 20: 2)$. About $150 \mu \mathrm{g}$. of lipid was applied, and following a $10 \mathrm{~cm}$. migration, the spots were identified by staining with iodine vapour. They were then scraped from the plate, and the amount of organic material in the fatty acid and triglyceride fractions was estimated by the method of Amenta (1964). The amount of organic material in the partial glyceride fraction of the chromatograms was not estimated because of the close proximity of cholesterol to diglyceride and of monoglyceride to the material remaining at the origin. The degree of lipolysis suggested by the size and intensity of the spots for triglyceride and its digestion products was consistent with the calculated fatty acid: triglyceride ratio which was used only as an index of lipolysis.

\section{RESULTS}

Virtually no emulsified olive oil was absorbed in the absence of both bile and pancreatic juice. In this group the amount of fat recovered was equal to the amount of olive oil infused plus the amount present after a fat-free saline infusion (endogenous fat) (Fig. 1 and Table I). Addition of taurocholate appeared to bring about improvement in the absorption of olive oil, but the difference was not statistically significant. However, on returning taurocholate plus bicarbonate, the recovery of fat was not significantly different from the controls, i.e., absorption was normal, despite the absence of pancreatic enzymes.

Oleic acid was equally well absorbed in all groups (Fig. 2 and Table II). There were no statistically significant differences between recoveries.

The values for the saline-infused groups are given in Table III. They represent the 'endogenous fat' for each group, and although they suggest that the value is increased in the absence of bile and pancreatic

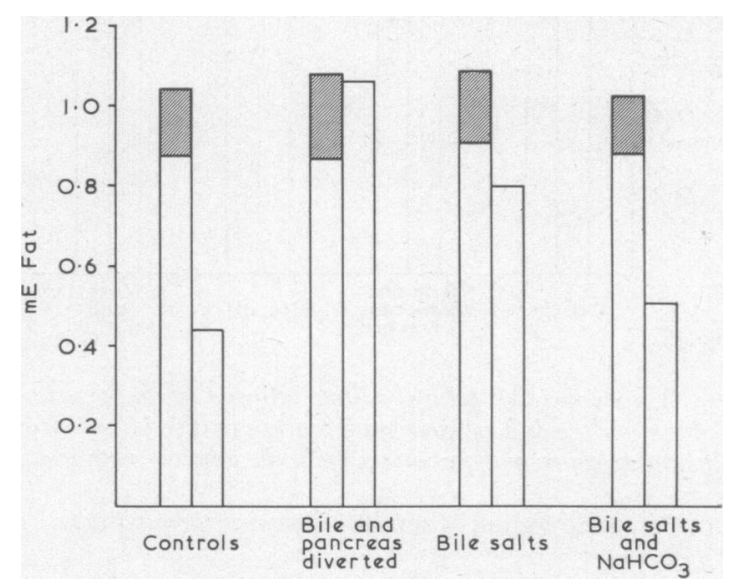

FIG. 1. Recoveries following infusion of olive oil. Column on left of each pair represents fat infused plus endogenous, and that on the right the amount recovered.

TABLE I

RECOVERIES OF SAPONIFIABLE FAT FOLLOWING FOUR-HOUR INFUSION OF OLIVE OIL ${ }^{1}$

Controls

$\begin{array}{rr}27 & (8.7) \\ 308 & (87.4) \\ 115 & (65 \cdot 7) \\ 450 & (77 \cdot 8)\end{array}$

Total

'Results expressed in $\mu$ Eq. Mean and S.E.M.

\section{Stomach}

Small intestine
Bile and Pancreas Diverted 
TABLE II

RECOVERIES OF SAPONIFIABLE FAT FOLLOWING FOUR-HOUR INFUSION OF OLEIC ACID

\begin{tabular}{|c|c|c|c|c|c|c|c|c|}
\hline \multirow[b]{2}{*}{$\begin{array}{l}\text { Stomach } \\
\text { Small intestine } \\
\text { Caecum }\end{array}$} & \multicolumn{2}{|c|}{ Controls } & \multicolumn{2}{|c|}{$\begin{array}{l}\text { Bile and Pancreas } \\
\text { Diverted }\end{array}$} & \multicolumn{2}{|c|}{ Bile Salts Returned } & \multicolumn{2}{|c|}{$\begin{array}{l}\text { Bile Salts Plus } \\
\text { Bicarbonate }\end{array}$} \\
\hline & $\begin{array}{r}49 \\
311 \\
83\end{array}$ & $\begin{array}{l}(19 \cdot 3) \\
(110 \cdot 1) \\
(32 \cdot 0)\end{array}$ & $\begin{array}{r}36 \\
479 \\
130\end{array}$ & $\begin{array}{l}(20 \cdot 0) \\
(36 \cdot 8) \\
(18 \cdot 0)\end{array}$ & $\begin{array}{r}26 \\
417 \\
124\end{array}$ & $\begin{array}{l}(11 \cdot 0) \\
(32 \cdot 8) \\
(9 \cdot 5)\end{array}$ & $\begin{array}{r}26 \\
371 \\
188\end{array}$ & $\begin{array}{l}(7 \cdot 8) \\
(15 \cdot 9) \\
(45 \cdot 2)\end{array}$ \\
\hline Total & 443 & $(138 \cdot 2)$ & 645 & $(50 \cdot 8)$ & 566 & $(14 \cdot 7)$ & 585 & $(57 \cdot 6)$ \\
\hline
\end{tabular}

TABLE III

RECOVERIES OF SAPONIFIABLE FAT FOLLOWING INFUSION OF $0.85 \%$ SALINE FOR FOUR HOURS (ENDOGENOUS FAT)

\begin{tabular}{|c|c|c|c|c|}
\hline & Controls & $\begin{array}{l}\text { Bile and Pancreas } \\
\text { Diverted }\end{array}$ & Bile Salts Returned & $\begin{array}{l}\text { Bile Salts Plus } \\
\text { Bicarbonate }\end{array}$ \\
\hline $\begin{array}{l}\text { Stomach } \\
\text { Small intestine } \\
\text { Caecum }\end{array}$ & $\begin{array}{ll}12 & (2 \cdot 2) \\
57 & (4 \cdot 8) \\
78 & (14 \cdot 4)\end{array}$ & $\begin{array}{rr}10 & (1 \cdot 1) \\
58 & (2.9) \\
146 & (13.4)\end{array}$ & $\begin{array}{rr}8 & (3 \cdot 1) \\
35 & (5 \cdot 4) \\
129 & (21 \cdot 8)\end{array}$ & $\begin{array}{ll}11 & (4.5) \\
33 & (9.2) \\
92 & (16.0)\end{array}$ \\
\hline Total & $147 \quad(16.9)$ & $213 \quad(35 \cdot 5)$ & $172(17 \cdot 3)$ & $136(7.7)$ \\
\hline
\end{tabular}

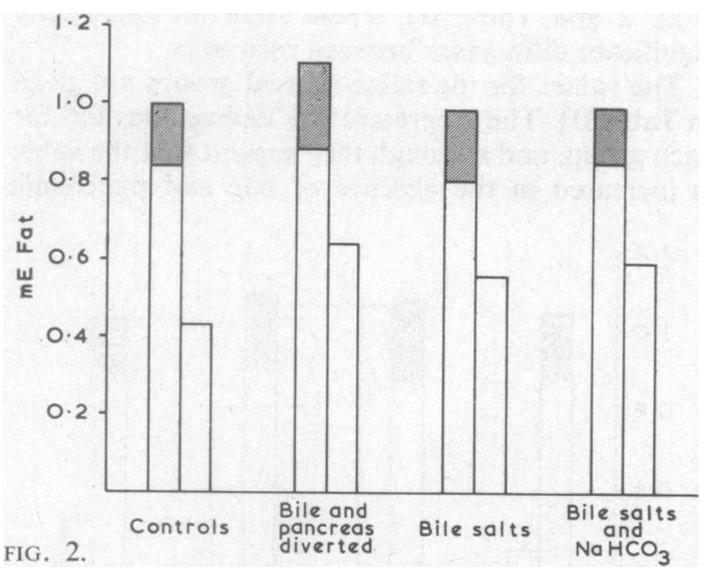

FIG. 2. Recoveries following the infusion of oleic acid. Column on the left of each pair represents the fat infused plus endogenous, and that on the right the amount recovered.

FIG. 3. Scattergram of results of lipase determinations.

juice, the differences are not significant with the numbers involved.

The test for trypsin was always positive in animals without bile-pancreatic fistulae, and negative in fistula animals. However, a small amount of residual lipolytic activity was detected in the intestinal contents although activities were very low compared with those in animals without fistulae (Fig. 3). Injected preparations of the duct system of the pancreas had failed to show any major ducts which might have escaped ligation. In an attempt to determine the source of this residual lipolytic activity, the affect of $p \mathrm{H}$, taurocholate, and esterified
FIG. 3 .

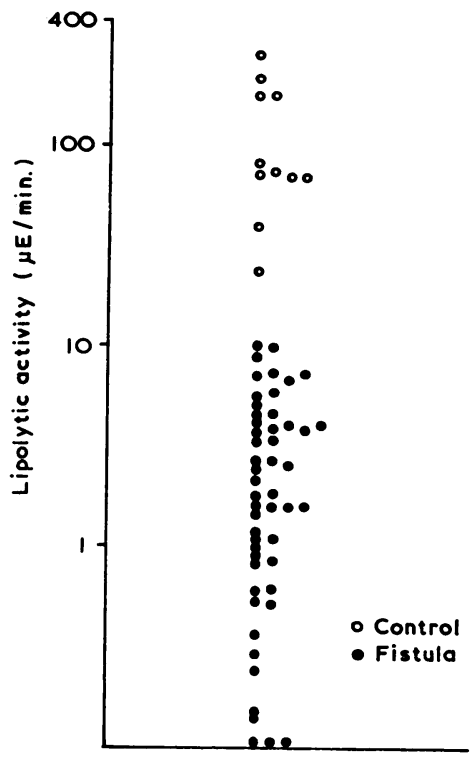

fatty acid chain length on the rate of lipolysis was compared in intestinal contents from animals with and without bile-pancreatic fistulae. In both cases the rate of the lipolysis was increased threefold by $1 \%(w / v)$ sodium taurocholate. The optimum $p \mathrm{H}$ for lipolysis was the same for intestinal contents from normal animals as for contents from animals with fistulae, as was the pattern of activity against triglycerides of long-and short-chain fatty acids (Figs. 4 and 5).

To determine whether the addition of taurocholate or taurocholate plus bicarbonate altered the degree of residual lipolytic activity, the composition of the 


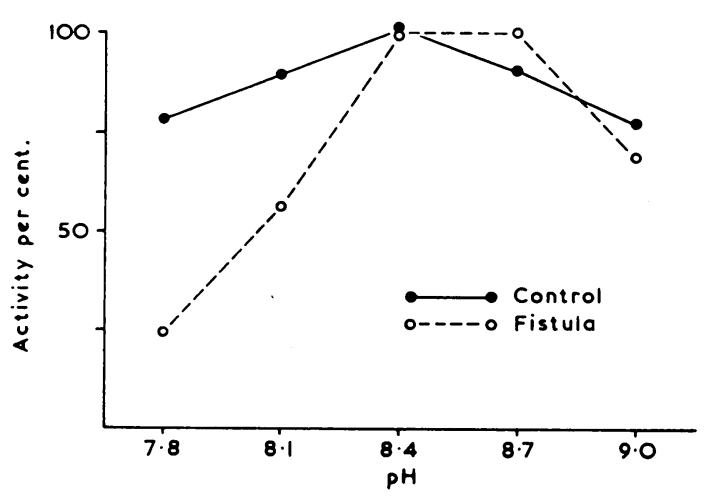

FIG. 4. Effect of $p H$ on activity of lipases found in diverted and control animals. Each curve is the result of two similar experiments averaged.

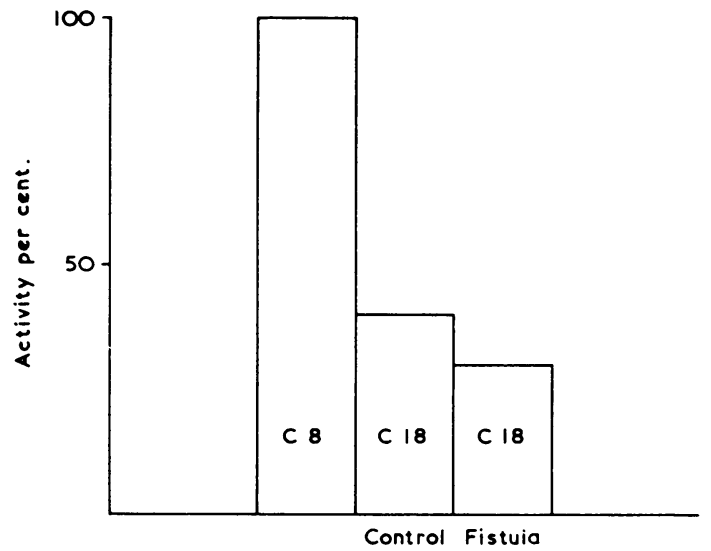

FIG. 5. Relative activity of pancreatic and residual lipase against triglycerides of chain length 8 and 18. Activity against $C 8=100 \%$.

test meal and of intestinal contents after infusion of emulsified olive oil for four hours was examined by thin-layer chromatography. Two animals were studied in each of four groups, with duplicate thinlayer chromatographic analyses on each animal. The appearances of the stained chromatograms and the results of analysis for material in free fatty acid and triglyceride spots were consistent between duplicates and between animals in each group. Since the analyses were used only to give an index of lipolysis in a small number of animals the results will not be presented in detail. In the test meal, the free fatty acid spot contained about $10 \%$ as much material as the triglyceride spot. There was a trace of diglyceride. In animals without pancreatic fistulae, the intestinal washings contained one and a half times as much free fatty acid as triglyceride. In animals with pancreatic fistulae, whether bile and bicarbonate were replaced or not, the intestinal washings contained about the same proportion of free fatty acid to triglyceride as in the test meal, varying from about $1: 5$ to $1: 10$ between the different groups. Interpretation of these results must take into account the rate of absorption in the control and experimental groups and will be considered in the discussion.

\section{DISCUSSION}

In agreement with Kim and Bollman (1954), it was found that virtually no triglyceride was absorbed in the absence of both bile and pancreatic juice. In the present experiments the triglyceride was given as a fine emulsion, with most of the particles less than $0.3 \mu$ in diameter, which remained stable in the lumen. This seems to be strong evidence against the absorption of triglyceride as such, e.g., by pinocytosis.

The absorption of finely emulsified fatty acid was not significantly decreased in pancreatic fistula animals nor was it affected in these animals by return of bile salts, with or without bicarbonate. If fatty acids are absorbed in the micellar state (Hofmann and Borgström, 1962), it would seem that the artificial emulsifier was en efficient substitute, in the present experiments, for the amphipaths of bile, even in the absence of bicarbonate.

For the reasons just mentioned, the improvement in absorption of emulsified triglyceride when bicarbonate with bile salts was returned was probably due to acceleration of residual lipolytic activity in rats with pancreatic fistulae. The results of thinlayer chromatography of intestinal contents lend some support to this opinion. Rats with pancreatic fistulae and no replacement of bile salts or bicarbonate absorbed virtually no triglyceride. The ratio of free fatty acid to triglyceride on the chromatogram was about 1:5 compared with $1: 10$ in the test meal. Very little triglyceride could have been hydrolysed in the intestine by the 'residual' lipolytic activity during the four-hour infusion. When bile salts with bicarbonate were returned the ratio was the same as without replacements. But fat was absorbed as rapidly as normally, presumably as fatty acid and monoglyceride, so lipolysis must have been faster than without replacements. Lipolysis was slower than in normal animals, in which the fatty acid : triglyceride ratio was $3: 2$ in the lumen after olive oil infusion for four hours. However, it was clearly rapid enough to permit a normal rate of absorption.

The origin of the residual lipolytic activity in animals with external pancreatic fistulae was not 
conclusively determined. Injection studies of the pancreatic ducts in 10 rats with India ink and barium sulphate suspension failed to reveal accessory ducts which might have escaped cannulation or ligation by the cannula ties. None of the rats in the present series showed clinical or post-mortem evidence of any obstruction to the fistula. Non-pancreatic lipases have been described and the existence of one or more in the epithelium of the small intestine been well established, (Tidwell and Johnston, 1960; DiNella, Meng, and Park, 1960; McPherson, Askins, and Pope 1962; Senior and Isselbacher, 1963). These lipases appear to differ from that of the pancreas; for example, DiNella et al. found that their mucosal enzyme was relatively more active against triglyceride of shorter chain length than was pancreatic lipase, and that it was equally active against triglyceride, diglyceride, and monoglyceride, whereas it is well known that pancreatic lipase is relatively more active against the higher glycerides. No differences were found between the activity in normal intestinal contents and that of diverted animals in these experiments. The possibility cannot be excluded, therefore, that pancreatic enzymes entered the lumen in small amount, insufficient to give a positive test for trypsin but sufficient to give appreciable lipolysis. Digestion may be virtually normal in rats with only $1 \%$ of the pancreas remaining (Uram, Friedman, and Kline, 1960) so it should appear that pancreatic exclusion was complete for practical purposes in the present experiments.

\section{SUMMARY}

The presence of bile or pancreatic juice is essential for the absorption of triglyceride but not for that of fatty acid.

The absorption of triglyceride which occurs in the absence of pancreatic juice, and in the presence of bile salts, probably follows hydrolysis.

In pancreatic-deficient animals, some lipolytic activity remains in the small intestine, which could account for the absorption of triglyceride. This absorption can be improved by returning alkali.
The authors are indebted to Miss M. Donovan and Miss C. Limpus for competent technical assistance and to Mr. C. Boundy of the C.S.I.R.O. for help with the statistical analysis.

\section{REFERENCES}

Aberdeen, V., Shepherd, P. A., and Simmonds, W. J. (1960). Concurrent measurement, in unanaesthetized rats, of intestinal transport and fat absorption from the lumen. Quart. J. exp. Physiol., 45, 265-274.

Amenta, J. S. (1964). A rapid chemical method for quantification of lipids separated by thin-layer chromatography. J. Lipid Res., 5, 270-272.

Andersen, D. H., and Early, M. V. (1942). Method of assaying trypsin suitable for routine use in diagnosis of congenital pancreatic deficiency. Amer. J. Dis. Child., 63, 891-893.

Borgström, B., Lundh, G., and Hofmann, A. (1963). The site of absorption of conjugated bile salts in man. Gastroenterology, 45, 229-238.

Cohen, B. J. (1961). Fat excretion in dogs lacking both bile and pancreatic juice. Proc. Soc. exp. Biol. (N.Y.), 107, 40-42.

- and Annegers, J. H. (1953). Fecal loss of various dietary nutrients in dogs lacking pancreatic juice. Gastroenterology, 25, 67-71.

Desnuelle, P., Constantin, M. J., and Baldy, J. (1955). Technique potentiométrique pour la mesure de l'activité de la lipase pancréatique. Bull. Soc. Chim. Biol. (Paris), 37, 285-290.

DiNella, R. R., Meng, H. C., and Park, C. R. (1960). Properties of intestinal lipase. J. biol. Chem., 235, 3076-3081.

Hofmann, A. F., and Borgström, B. (1962). Physico-chemical state of lipids in intestinal content during their digestion and absorption. Fed. Proc., 21, 43-50.

Kamer, J. H. van de, Huinink, H. ten Bokkel, and Weyers, H. A. (1949). Rapid method for the determination of fat in feces. J. biol. Chem., 177, 347-355.

Karvinen, E., Lin, T. M., and Ivy, A. C. (1957). Function of pancreatic juice in fat utilization in the rat. Amer. J. Physiol., 189, 113-116.

Kim, K. S., and Bollman, J. L. (1954). Absorption of fat in the absence of both bile and pancreatic juice. Arch. Surg., 69 , 247-254.

McPherson, J. C., Askins, R. E., and Pope, J. L. (1962). Specificity of an intestinal lipase for monoglycerides. Proc. Soc. exp. Biol. (N.Y.), 110, 744-748.

Pessoa, V. C., Kim, K. S., and Ivy, A. C. (1953). Fat absorption in absence of bile and pancreatic juice. Amer. J. Physiol., 174, 209-218.

Senior, J. R., and Isselbacher, K. J. (1963). Demonstration of an intestinal monoglyceride lipase: an enzyme with a possible role in the intracellular completion of fat digestion. J. clin. Invest. 42, 187-195.

Tidwell, H. C., and Johnston, J. M. (1960). An in vitro study of glyceride absorption. Arch. Biochem., 89, 79-82.

Tietz, N. W., Borden, T., and Stepleton, J. D. (1959). An improved method for the determination of lipase in serum. Amer. J. clin. Path., 31, 148-154.

Uram, J. A., Friedman, L., and Kline, O. L. (1960). Relation of pancreatic exocrine to nutrition of the rat. Amer. J. Physiol., 199, 387-394.

Vermeulen, C., Owens, F. M., Jr., and Dragstedt, L. R. (1943). The effect of pancreatectomy on fat absorption from the intestines. Amer. J. Physiol., 138, 792-796. 